\title{
TRIANGULATION WITHOUT TEARS
}

Jillian Farquhar, Guildhall Faculty of Business \& Law, London Metropolitan University, 84 Moorgate, LONDON EC2M 6SQ, UK.j.farquhar@londonmet.ac.uk.

Nicolette Michels, Business School, Oxford Brookes University, OXFORD OX33 1HX, UK. nmichels@brookes.ac.uk.

Professor Jillian Farquhar leads the doctoral programme in London Guildhall School of Business. Her research interests include marketing strategy particularly in the marketing of financial services as well as case study research methods. She has authored books, book chapters and papers and edited a leading bank marketing journal. She is Senior Associate of the Centre for Risk, Banking and Financial Services at the University of Nottingham. Current research interests include branding and case study research methods.

Dr Nicolette Michels is MBA Programme Lead in the Business Faculty at Oxford Brookes University. Nicolette's research interests draw on a range of disciplinary areas including Marketing, Enterprise, Organisational Management and Knowledge Exchange. Incorporating experience of conducting research, consultancy and mentoring in, with and for academic, public and private sector stakeholders, Nicolette is interested in supporting meaningful knowledge work between the academic and wider communities. 


\begin{abstract}
This paper examines the role of triangulation in claims for rigour in case study research. Case study research has been criticised for its lack of rigour and researchers have been advised to use triangulation as part of their rigour processes. Although triangulation is frequently referred to in qualitative research, the detail of how it enhances rigour in case study research is somewhat elusive. This paper argues that there are three potential outcomes of triangulation processes in case study research; convergence, complementarity or divergence. These outcomes are all consistent with triangulation but offer new perspectives on how triangulation supports rigour in case study research.
\end{abstract}

Key words: case study research; rigour; triangulation; convergence; complementarity; divergence.

A version of this paper has been published as

Farquhar, J. and Michels, N. (2016), Triangulation without Tears, Marketing Challenges in a Turbulent Business Environment, in (eds) M. Groza and C. Ragland, Springer, Heidelberg, pp.325-330. 


\section{Introduction}

Case study research is well suited to investigating complexity (Eisenhardt, 1989, Yin, 2009) and generating context-dependent knowledge (Flyvbjerg, 2006) on which to base innovative strategies. In spite of these benefits, case study research has attracted criticisms primarily concerned with its rigour. Reviewers have pointed to case study research where little insight has been provided (Beverland and Lindgreen, 2010; Dubé and Paré, 1999). To respond, case study researchers need to emphasise the quality of the story whilst providing detail of careful analytical procedures (Eisenhardt, 1989), such as triangulation. The detail of triangulation however is somewhat elusive. The aim of this study is offer a perspective on triangulation in consistent with the aim of case study research and hence provide case study researchers and reviewers with contemporary insight into its role in rigour.

\section{Triangulation}

The principle of triangulation consists of obtaining a fix on the phenomenon under investigation from two known points. Although open to a number of perspectives, a classical view of triangulation in social sciences is that multiple and independent measures provide a more 'certain portrayal' of the phenomenon that is being studied (Jick, 1979 p604). In case study research, it is proposed that triangulation consists of multiple perspectives which converge on the phenomenon under investigation. In this way, bias is minimised and/or validity established (for example Yin, 2009; Modell 2005, 2009). Triangulation is often achieved through the assembly of multiple sources of data. These multiple sources are thought to provide a stronger substantiation of constructs and hypotheses as a means of grounding emerging theory (Eisenhardt, 1989). A prime exponent of triangulation, Denzin (1978) identified five types of triangulation (see Table 1). The first type is data triangulation, which refers to data collected using the same method but from different sources, for example interviews from different informants at different times or observation of different situations or 
contexts. A multiplicity of data sources is also considered to confer a degree of convergent validity on the research (Jick, 1979) or enhanced confidence (Bryman, n.d.). In qualitative research, where two or more data sets are used for corroboration or claims for external validity or reliability, the study gains impact (Bluhm et al. 2010). Investigator or researcher triangulation consists of multiple researchers collecting and interpreting evidence. This type of triangulation might loosely correspond to inter-rater reliability as advised for demonstrating rigour case study research (see for example Voss et al. 2002). In theoretical triangulation, it is thought that greater insight may be gained from looking at a data set from a number of theoretical perspectives. However, recourse to more than one theory in seeking explanations is commonplace and is dismissed as not necessarily being an example of theoretical triangulation (Swanborn, 2010). Nonetheless, there may be some resonance with enfolding the literature as advocated by Eisenhardt (1989) where unexpected theoretical avenues open up. The fourth type of triangulation is methodological, which as the table indicates, is either within-method or between-method. Within-method triangulation consists of multiple techniques within a given methodology, for example, qualitative evidence from focus groups and archival analysis or establishing validity through confirmatory factor analysis (Homburg et al. 2012). Between-method triangulation uses different methods and might consist of a survey of an appropriate sample and semi-structured interviews, thus from two different methodological stances. This type appears to be the same as Miles and Huberman's (1994) triangulation by data type. The rationale for between method triangulation in particular is that the use of more than one method compensates for the weaknesses of the other one. Between-method triangulation comprises contrasting methods, that is, qualitative and quantitative and is therefore characteristic of mixed methods research (Fielding, 2009) rather than case study investigation. 


\begin{tabular}{ll}
\hline Category & Description \\
\hline Data & Similar data gathering from different sources, possibly at \\
& different times on the same object, entails gathering data \\
& through several sampling strategies, so that slices of data at \\
& different times and social situations, as well as on a variety \\
& of people. \\
& More than one researcher involved in gathering and often \\
Investigator/researcher & interpretation of data with same objective. \\
& Use of more than one theoretical perspective in the \\
Theoretical & interpretation of sources. \\
Methodological or data & Within-method (varieties of same method) used in study. \\
type & Between-method (different methods) with same objective, \\
& e.g. mix of quantitative and qualitative. \\
Perceptual & Perceptions of actors and observer supplemented with \\
& secondary data.
\end{tabular}

Compiled from Bonoma (1985); Bryman, (n.d); Denzin (1978); Erzburger and Prein (1993);

Flick (1992); Jick (1979); Miles and Huberman (1994).

However seductive triangulation may sound in its ability to strengthen findings, it has proved less easy to put into practice. Denzin (2010) has recently revisited the topic and considers triangulation to be unsettling and unruly. An immediate difficulty arises from transposing triangulation from its geometrical home to social sciences (Blaikie, 1991; Swanborn, 2010) so that perspectives and practices of triangulation are subject to the ontological and epistemological stances of the researchers. However arguments related to incommensurability apply to between methods triangulation leading to calls for an alternative epistemological perspective such as critical realism (see for example Easton, 2010; Olsen, 2004). Epistemological concerns cannot be side-lined however when thinking about the rigour claims that can be made on the basis of triangulation. Triangulation has, for example been perceived through the language of capture and constraint with the underlying assumption 
that phenomena can be represented objectively (Wolfram Cox and Hassard, 2010). A subjectivist view of triangulation would support revelations of multiple constructed realities (Seale, 1999; Silverman, 2006) or, as Flick (1992) describes it, a kaleidoscope. Thus the findings of a study may not converge but they may complement each other or even diverge (Erzberger and Prein, 1997) thus enriching the kaleidoscope. Triangulation takes its cue from the paradigmatic assumptions of the researcher or the nature of study, which in turn dictate the rigour issues that it is deployed to address. Triangulation, accordingly, can support claims for validity and reliability as advocated by Yin (2009) or confirmability in naturalistic research (Wallendorf and Belk, 1989). Whatever the epistemological stance of the researchers, triangulation should operate according to ground rules, beginning from the robust theoretical models and choosing methods and empirical materials that complement that perspective (Silverman, 2005). As Denzin (2010) has recently written, triangulation like many other aspects of research is subject to evolution and re-appraisal, therefore, it is appropriate to re-evaluate triangulation and its role in strengthening rigour in case study research.

\section{Triangulation in case study research}

According to Yin (2009), case study research is an empirical inquiry that investigates a contemporary phenomenon in depth and within its real-life context. Across the epistemological perspectives, there is support for this definition, with consensus on the study of phenomena linking the theoretical with the empirical (Ragin, 1992), that the study is bounded to some extent and that the study is in a specific context (Creswell, 2007; Miles and Huberman, 1994; Swanborn, 2011). Among quality processes in case study research such as access to raw data and explanation of negative cases, triangulation is widely recommended (Beverland and Lindgreen, 2010; Dubé and Paré, 2003; Eisenhardt and Graebner, 2007; Gibbert and Ruigrok, 2010). Specifically, triangulation can address validity (Beverland and 
Lockshin, 2003; Yin, 2009) and reliability (for example Miles and Huberman, 1994). A case study can claim a degree of construct validity by triangulating the number of data sources that have been assembled as part of the case or cases (Beverland and Lockshin, 2003; Yin, 2009). Triangulation is thought to support internal validity (Dubé and Paré, 2003) and convergent validity (Jick, 1979). It has even been asserted that the greater the number of sources, the greater the construct validity (Dubois and Gibbert, 2010). These arguments will rest of course on how robustly the measures or constructs have been operationalized in the first place (Swanborn, 2010). In qualitative research, strong support for triangulating data sources comes from Bluhm et al. (2010), who found that studies involving multiple data collection methods have a greater influence on management than single-method studies. Further assertions for triangulation include substantiation (Stake, 1995), trustworthiness (Wallendorf and Belk, 1989) and reduced vulnerability to errors (Patton, 1989). Given this extensive support for triangulation, there is an expectation that case study researchers will engage in one form of triangulation as a means of strengthening their research findings. What might be the process of triangulation in case study research?

As has been stated above, aligning the claims and process of triangulation in case study research to the epistemological approach (Blaikie, 1991) of the study is necessary. A broadly positivist study may include an explanation of how triangulation supports claims for validity and reliability, whereas a non-positivist investigation may shape arguments around how triangulation enhanced the evaluation of alternative explanations (for example Patton, 1989) or credibility (Sonenshein, 2010). Following Eisenhardt's suggestions (1989), detail of the triangulation process must be evident and might include the delineation of the relationship between the sources, for example, if there is there a primary source and why is it primary (Bryman n.d.). For example, Walsh and Bartunek (2011) triangulated their interview data 
with archives to verify the trustworthiness of their research. The contribution of remaining sources should be clearly articulated and details of analysis explicitly stated (see for example Clark et al. 2010). Whilst research has indicated that many case studies published in high quality journals do not afford a clear epistemological stance (Gibbert and Ruigrok, 2011), there are often statements about theory building (for example Gioia et al. 2010) or theory elaboration (for example Lepoutre and Valente, 2012). Positivist researchers will initiate the process of triangulation by developing a priori categories or establishing one particular source as being primary (Bryman n.d.) so that validity and reliability can be asserted. For nonpositivist researchers, triangulation becomes 'a way of life', that is, an incessant cycle of checking and reflection (Miles and Huberman, 1994).

\section{Triangulation outcomes in case study research}

Whatever the orientation of the researcher, it is unlikely that a perfect fit of data, sources, processes or theory will be achieved and what does this less than perfect fit signify for the contribution of the study? How does triangulation work in situations where there is some disjunction? We contend that the triangulation literature overly emphasises the requirement for sources to converge (for example Greene et al .1989), to correlate (Homburg et al. 2012) or corroborate (Miles and Huberman, 1994). Whilst convergence is desirable in the original discipline of geometry, it may be less so in the social sciences, even where a positivist epistemology prevails. Indeed, there may well be a spectrum of outcomes of triangulation ranging from convergence to more complex results which contribute nonetheless to the aims of the case study research and which are more or less consistent with the epistemological trajectory of the study. We propose three potential outcomes of triangulation: convergence, complementarity and divergence. 


\section{Convergence}

As we comment above, the logic of triangulation is predicated on findings that converge. Converging findings increase the likelihood of theoretical concepts and their operational definitions capturing various empirical phenomena with greater precision (Modell, 2009) and encourage researchers to have greater confidence in the reliability and/or validity of the research (Wolfram Cox and Hassard, 2010). It is assumed that between methods research will yield convergent findings such as two or more distinct methods yield comparable data (Jick, 1979). Between methods research is often justified on the basis that the use of qualitative research balancing deficiencies in quantitative and vice versa. Nonetheless, it is probably more important to positivist researchers that the sources of their study converge so that triangulation supports claims for validity and an objective reality.

\section{Complementarity}

Complementarity can be a feature of triangulation where quantitative and qualitative methods do not generate one complete picture but instead an adequate image of reality (Erzburger and Prein, 1993). Complementary findings generate a measure of overlapping but different facets of a phenomenon so that an enriched understanding is gained (Greene et al. 1989). Although Greene et al. (1989) propose complementarity as distinct from triangulation, their view of triangulation is rather narrowly focused on convergence. It is, however, important to ensure that the theoretical assumptions of the research are well founded (Erzburger and Prein, 1993). Complementarity has a wide appeal to case study researchers as it seems to have a particular resonance to the complexity and in-depth nature of the research strategy.

\section{Divergence}

Divergent findings may not necessarily be an indication of flawed research but may signal something of interest or significance in the case study investigation. Divergent results provide the opportunity for enriching case study research work (Flyvbjerg, 2006) and 
strengthening its contribution (for example; Patton, 1989). There are instances of where divergent findings have uncovered unseen factors (Jick, 1979) and where they seem consistent with thick description and rich data. Divergence in the results can lead to clearer definition and theoretical elaboration (Wolfram Cox and Hassard, 2010). In case study research particularly, divergent findings support other methods of establishing rigour such as negative cases (Beverland and Lindgreen, 2010), creative use of setbacks (Gibbert and Ruigrok, 2011) or alternative explanations (Patton, 1989). Non-positivist researchers may be more attuned to divergent findings from their sources, as they may be seeking multiple realities. Also the attention to anomalies in data can be used to interrogate existing theoretical perspectives (Hesse-Biber, 2010).

Figure $1 \quad$ Triangulation outcomes in case study research

The aim of triangulation is therefore not necessarily harmonious findings but to support the aim of case study research in theory building, which may be better achieved through finding something that does not fit.

\section{Conclusions}

In this paper, we assert that an in-depth understanding of complex problems as provided by case study research can provide valuable insight. Case study has been accused of lacking in rigour and triangulation has been proposed as a means of addressing that perceived lack rigour. Claims for triangulation are many and varied prompting us to investigate how it can strengthen case study research with specific reference to the management of multiple sources. We propose three approaches of convergence, divergence or complementarity to addressing the outcomes of triangulation. For these approaches to work effectively, claims for triangulation need to be aligned the overall epistemological stance of the study. 
The linkages that we make between the claims for triangulation and epistemological stance of study are as yet unexplored and suggest an important area for study. A further area for attention is the conclusions that might be drawn from a case study where sources are not triangulated? Such is the weight of literature in support of triangulation in case study research that its omission provokes questions about the rigour of the study. How have the researchers argued for the rigour of the study? Further research can investigate how high quality studies that have not used triangulation have argued for the quality of their study. 


\section{References}

Beverland, M. \& Lockshin, L. (2003). A longitudinal study of customers' desired value change in business-to-business firms. Industrial Marketing Management, 35(3), 383-393.

Beverland, M. \& Lindgreen, A. (2010), What makes a good case study? A positivist review of qualitative case research published in Industrial Marketing Management, 1971-2006. Industrial Marketing Management, 39, 56-63.

Blaikie, N. (1991), A critique of the use of triangulation in social research, Quality and Quantity, 25, 115-136.

Bluhm, D., Harman, W., Lee, T. \& Mitchell, T. (2011), Qualitative Research in Management: A Decade of Progress, Journal of Management Studies, 48(8) 1699-1923.

Bonoma, T. (1985), Case Research in Marketing: Opportunities, Problems and a Process, Journal of Marketing Research, 2, 199-208.

Bryman, A. (n.d.), Triangulation, retrieved from www.referenceworld.com/sage/socialscience/triangulation.pdf, 24/04/2013.

Bryman, A. (2006), Integrating quantitative and qualitative research: how is it done? Qualitative Research, 6(1) 97-113.

Denzin, N. (1978), The Research Act, Chicago, Aldine.

Denzin, N. (2010), Moments, Mixed Methods, and Paradigm Dialogs, Qualitative Enquiry, 16(6) 419-427.

Dubé, L \& Paré, G. (2003), Rigor in Information Systems Positivist Case Research; Current Practices, Trends and Recommendations, MIS Quarterly, 27 (4) 597-635

Dubois, A \& Gibbert, M. (2010), From complexity to transparency: managing the interplay between theory, method, and empirical phenomena in IMM case studies, Industrial Marketing Management, 39, 129-136. 
Erzberger, C. and Prein, G. (1997), Triangulation; validity and empirically based hypothesis construction, Quality and Quantity, 31, 141-154.

Fielding, N. (2009), Going out on a Limb: Postmodernism and Multiple Method Research, Current Sociology 57(3), 427-447.

Fielding, N. (n.d.), www.qualitativeresearch.net/index.php/fqs/article/viewArticle/965/2106\#g3, accessed 09/11/13.

Flick, U. (1992), Triangulation Revisited: Strategy of Validation or Alternative, Journal of the Theory of Social Behaviour, 22(2) 175-197.

Flyvbjerg, B. (2006). Five Misunderstandings About Case Study Research. Qualitative Inquiry, 12(2) 219-245.

Gibbert, M. \& Ruigrok, W. (2010), The What and How of Case Study Rigor: Three strategies based on Published Work. Organizational Research Methods, 13(4), 710-737.

Gioia, D., Price, K. Hamilton, A. \& Thomas, J. (2010). Forging an Identity: An Insideroutsider Study of Processes Involved in the Formation of Organizational Identity, Administrative Science Quarterly, 55, 1, 1-46.

Greene, J., Caracelli, V. and Graham, W. (1989), Toward a Conceptual Framework for Mixed-Method Evaluation Designs, Educational Evaluation and Policy Analysis, 11, 3, 255-274.

Homburg, C., Klarmann, M., Reimann, M. and Schilke, O. (2012), What Drives Key Informant Accuracy, Journal of Marketing Research, XLIX, 594-608.

Jick, T. (1979), Mixing Qualitative and Quantitative Methods: Triangulation in Action, Administrative Science Quarterly, 24(4), 602-611.

Miles, M. \& Huberman, A. (1994), Qualitative Data Analysis (2 ${ }^{\text {nd }}$ Edition), Thousand Oaks, Sage Publications. 
Modell, S. (2005), Triangulation between case study and survey methods in management accounting research: an assessment, Management Accounting Research, 16, 231-254.

Modell, S. (2009), In defence of triangulation: A critical realist approach to mixed methods research in management accounting, Management Accounting Research, 20, 208-221.

Patton, M. (1999), Enhancing the Quality and Credibility of Qualitative Analysis. Health Services Research, 34(5), 1189-1208.

Seale, C. (1999), Quality in Qualitative Research, Qualitative Inquiry, 54, 465-478.

Silverman, D. (2006), Interpreting Qualitative Data: Methods for Analysing Talk, Text and Interaction, 3rd Edition. London: Sage.

Stake, R E (1995), The Art of Case Study Research. Thousand Oaks, Sage Publications.

Swanborn, P. (2010), Case Study Research: what, why and how? London, Sage Publications.

Verschuren, P. (2003), Case study as research strategy: some ambiguities and opportunities. International Journal of Research Methodology, 6(2), 121-139.

Voss, C., Tsikriktsis, N. \& Frohlich, M. (2002), Case research in operations management, International Journal of Operations \& Production Management, 22(2) 195-219.

Wallendorf, M. \& Belk, R. (1989), Assessing Trustworthiness in Naturalistic Consumer Research. Special Volumes-Interpretive Consumer Research, Association for Consumer Research, 69-84.

Wolfram Cox, J. \& Hassard, J. (2010), Triangulation, in Encyclopaedia of Case Study Research II, (Eds) A. Mills, G. Durepos \& E. Wiebe, Sage, Thousand Oaks, CA. 944-948. Yin, R. (2009), Case Study Research: Design and Methods (4th Edition), Thousand Oaks, Sage Publications. 